\title{
Skip lateral Iymph node metastasis leaping over the central neck compartment in papillary thyroid carcinoma
}

\author{
Jianyong Lei ${ }^{1}$, Jinjing Zhong ${ }^{2}$, Ke Jiang ${ }^{1}$, Zhihui $\mathbf{L i}^{1}$, Rixiang Gong ${ }^{1}$, Jingqiang Zhu ${ }^{1}$ \\ ${ }^{1}$ Thyroid and Parathyroid Surgery Center, West China Hospital of Sichuan University, Chengdu 610041, China \\ ${ }^{2}$ Department of Pathology, West China Hospital of Sichuan University, Chengdu 610041, China \\ Correspondence to: Jingqiang Zhu, email: zjadoctor@163.com
}

Keywords: papillary, thyroid carcinoma, skip metastasis, lymph node, metastasis

Received: October 13, 2016

Accepted: January 16, 2017

Published: February 16, 2017

Copyright: Lei et al. This is an open-access article distributed under the terms of the Creative Commons Attribution License (CC-BY), which permits unrestricted use, distribution, and reproduction in any medium, provided the original author and source are credited

\section{ABSTRACT}

Objective: This study was performed to investigate the frequency and pattern as well as the predictive factors of skip metastasis (lateral cervical lymph node metastasis without central lymph node metastasis) in papillary thyroid carcinoma (PTC).

Methods: 450 PTC patients who received total thyroidectomy with central neck dissection(CND) combined with modified radical lateral neck dissection(LND) were divided into two groups: with or without skip metastases. The clinicopathological characteristics were statistically compared and analyzed, and univariate and multivariate analyses were performed to detect the risk factors of skip metastasis.

Results: The skip metastasis rate was $8.7 \%(39 / 450)$, and patients with skip metastases had fewer lateral lymph node metastases but were more likely to have single-level lateral metastasis, which are considered Level II $(P<0.05)$. Skip metastasis was significantly associated with the primary tumor location in the upper portion $(\mathrm{OR}=18.495,95 \%$ CI $6.612-51.731)$, a primary tumor size $\leq 10 \mathrm{~mm}(\mathrm{OR}=32.492$, 95\% CI 11.973-88.174) and Capsule invasion (OR=5.822, 95\% CI 1.954-17.343) as demonstrated by our prospective study of 10 patients who received an injection of $0.1 \mathrm{ml}$ carbon nanoparticles under ultrasonography in the upper portion of the lobe: $\mathbf{7}(\mathbf{7 0} \%)$ had lateral compartment lymph node black staining without ipsilateral center compartment lymph node staining. However, skip metastasis did not affect the PTC patients' long-term tumor-free survival rate $(P=0.432)$.

Conclusion: Skip metastases can be common, and the primary tumor location in the upper portion, a primary tumor size $\leq 10 \mathrm{~mm}$, and capsular invasion are closely linked to skip metastasis. The lateral compartment should be carefully evaluated.

\section{INTRODUCTION}

The worldwide incidence of thyroid cancer, especially papillary thyroid carcinoma (PTC), has increased rapidly in recent years $[1,2]$. Regional lymph node metastasis is commonly observed in PTC and occurs in approximately $30-80 \%$ of PTC patients [3, 4], even in Papillary thyroid microcarcinoma (PTMC, $\leq 10 \mathrm{~mm})[5,6]$, which may present an associated increased risk of regional recurrence and distant metastasis [7]. Previous studies reported that nodal metastasis of PTC occurs in a stepwise fashion, with metastasis beginning in the central cervical compartment, continuing to the ipsilateral cervical compartment, and finally arriving at the contralateral lateral or mediastinal compartment; therefore, the lateral compartment is the second site of PTC metastases [8]. However, negative metastasis in the central compartment and positive lateral compartment is often referred to as "skip metastasis", which is not uncommon in clinical PTC. The frequencies of skip metastasis reported in previous studies ranged from $6.8 \%$ to $37.5 \%$ [9-11].

To prevent recurrence and metastasis, the preoperative detection of lymph node metastasis and subsequent radical surgical removal must be performed. However, preoperatively detecting lymph node metastases remains a challenge, especially in the central lymph node (CLN) compartment, despite the development of advanced diagnostic tools, such 
as ultrasonography, enhanced computed tomography (CT) or magnetic resonance imaging (MRI). Skip metastases are more unpredictable [12], and their clinical significance remains unclear. Additionally, few studies have reported the prevalence, characteristics and risk factors of skip metastasis in PTC [9-11]. However, these previous studies were limited by small patient sample sizes and single center analyses. In addition, the skip metastasis rate differed greatly, and the risk factors that were reported varied greatly. Furthermore, credible predictive factors were not reported. In this study, we evaluated the frequency, pattern and predictive factors of skip metastasis within a large cohort of patients and used these data to support our clinical model.

\section{RESULTS}

\section{Patient demographics}

Of the 3668 patients whose medical records were reviewed, 450 met our study criteria and were included in our analysis. The mean age of the patients was $40.5 \pm 13.7$ years, and the male to female ratio was nearly 1:3 (120:330). The most common race was Han(442 cases, 98.2\%). Seventy five patients (16.7\%) had chronic diseases, such as hypertension, diabetes, etc. when undergoing surgery; and 8 patients (1.8\%)had Graves' disease; 211 patients(46.9\%) had nodular goiters; and 116 patients $(25.8 \%)$ had autoimmune thyroid disease when PTC was diagnosed (Table 1).

\section{Tumor characteristics}

As shown in Table 2, 74 (16.4\%) and 71 patients $(15.8 \%)$ presented multifocality and bilaterality, respectively. Papillary thyroid microcarcinoma (PTMC) was found in 96 patients(21.3\%). Pathological capsular invasion and extrathyroid extension was detected in 250 $(55.6 \%)$ and $130(28.9 \%)$ patients, respectively. PTCs were nearly evenly distributed in the three equal lobe areas, with $178(39.6 \%)$ in the upper portion, $133(29.6 \%)$ in the middle portion, $121(26.9 \%)$ in the lower portion, and $18(4 \%)$ were observed in the isthmus. Most of PTC cases were T3 (282 cases, 62.7\%), and 92 patients (20.4\%) had T4 because of the invasion of the recurrent laryngeal nerve (RLN), trachea, esophagus or prevertebral fascia. Additionally, 12 cases $(3.3 \%)$ were preoperatively diagnosed with distant metastasis, including 9 cases in the lung, 1 case in bone, and 2 cases in both lung and bone.

\section{Pattern of lymph node metastasis}

The mean number of total central neck lymph nodes was $11.0 \pm 3.0$, of which $5.9 \pm 3.2$ had metastases. Of these nodes, the mean number of ipsilateral central neck nodes was $6.3 \pm 2.1$, of which $3.5 \pm 2.1$ had metastases. Skip metastases were found in 39 patients $(8.7 \%)$. In the lateral compartment, the mean number of harvested lymph nodes was $15.9 \pm 7.2$, of which $6.4 \pm 2.8$ had metastases, and the most frequently involved sites were Levels III(75.3\%) and IV(72.9\%) followed by Levels II and V (as shown in Table 2). A further analysis revealed that double-level metastasis (181 cases, 40.2\%) was the most common model for lateral compartment metastasis, followed by triple-level metastasis (129 cases, 28.7\%), single-level metastasis (95 cases, 21.1\%) and four-level metastasis (45 cases, 10\%) (Table 3).

\section{Clinicopathological factors of skip metastasis in the lateral neck}

Significant clinicopathological factors that affect skip metastases occurring in the lateral compartment without central neck metastasis were identified and compared between the two groups in Table 3. The PTCs with skip metastases were more commonly detected with capsular invasion $(84.6 \%$ vs $52.8 \%, \mathrm{P}<0.001)$. A total tumor size $\leq 10 \mathrm{~mm}$ was more common in the skip metastases group $(71.8 \%$ vs $16.3 \%, \mathrm{P}<0.001)$, and a similar trend was observed for primary tumor size $\leq 10 \mathrm{~mm}$ (71.8\% vs $22.4 \%, \mathrm{P}<0.001)$. The skip metastases group showed more cases with a primary tumor located in the upper portion $(94.9 \%$ vs $34.3 \%, \mathrm{P}<0.001)$, and almost all of the PTC skip metastases were located in the upper portion except for 2 cases located in the middle portion (as shown in Table 3 ).

The lymph node metastasis rate and characteristics are shown and compared in Table 3. The PTC skip metastases showed a lower central neck node metastasis number $(\mathrm{P}<0.001)$ and ipsilateral central neck node metastasis number $(\mathrm{P}<0.001)$, even with comparable numbers of harvested nodes. Seven patients presented contralateral central lymph node metastasis with 10 lymph nodes overall, even without ipsilateral central neck lymph node metastases. In addition, the PTC skip metastasis presented a much lower lateral neck node metastasis $\mathrm{LN}$ number $(5.4 \pm 2.2$ vs $6.5 \pm 2.9, \mathrm{P}=0.015)$. The PTC skip metastases showed much higher Level II metastasis but much lower Level III, IV, and V metastases (all $\mathrm{P}<0.05$ ). The PTC skip metastases showed a much higher number of single-level metastases in the lateral compartment, much lower triple- and quadruple-level metastases in the lateral compartment $(\mathrm{P}<0.05)$ and comparable amounts of double-level metastases in the lateral compartment $(\mathrm{P}=0.110)$.

\section{Predictive factors of skip metastases}

The associations between skip metastases and the primary tumor location and size and capsular invasion were statistically significantly using univariate and multiple logistic regression analyses as shown in Table 4. The ORs for the primary tumor location in the 
Table 1: PTC Patient demographics and clinical characteristics $(n=450)$

\begin{tabular}{|c|c|}
\hline Characteristics & Results \\
\hline Age at diagnosis (mean $\pm \mathrm{SD}$, years) & $40.5 \pm 13.7$ \\
\hline$\leq 45$ years & 295 \\
\hline$>45$ years & 155 \\
\hline Sex (male/female) & $120 / 330$ \\
\hline Race (Han/Tibetan/Hui/Yi) & $442 / 6 / 1 / 1$ \\
\hline Height $(\mathrm{cm})$ & $163.7 \pm 7.2$ \\
\hline Weight (kg) & $61.4 \pm 10.9$ \\
\hline $\operatorname{BMI}\left(\mathrm{kg} / \mathrm{m}^{2}\right)$ & $22.8 \pm 3.3$ \\
\hline Chronic disease (no/hypertension/diabetes/both/other) & $375 / 60 / 6 / 4 / 5$ \\
\hline Autoimmune thyroid disease (yes/no) & $116 / 334$ \\
\hline Graves' disease (yes/no) & $8 / 442$ \\
\hline Nodular goiters (yes/no) & $211 / 239$ \\
\hline $\mathrm{NLR}($ mean $\pm \mathrm{SD})$ & $1.9 \pm 0.9$ \\
\hline$\leq 2$ & 291 \\
\hline$>2$ & 159 \\
\hline $\operatorname{PLR}($ mean \pm SD $)$ & $108.1 \pm 50.5$ \\
\hline$\leq 200$ & 218 \\
\hline$>200$ & 232 \\
\hline TSH level(mU/L, mean \pm SD) & $3.2 \pm 3.0$ \\
\hline FT4 level $(\mathrm{pmol} / \mathrm{L}$, mean \pm SD) & $17.5 \pm 6.1$ \\
\hline FT3 level(pmol/L, mean \pm SD) & $4.9 \pm 0.7$ \\
\hline
\end{tabular}

Abbreviations: SD: standard deviation; BMI: body mass index; NLR: neutrophil-to-lymphocyte ratio; PLR: platelet-tolymphocyte ratio; TSH: thyroid stimulating hormone; FT3: free triiodothyronine; FT4: free thyroxine

upper portion, primary tumor size $\leq 10 \mathrm{~mm}$ and capsular invasion were 18.495 (95\% CI 6.612-51.731), 32.492 (95\% CI 11.973-88.174) and 5.822 (95\% CI $1.954-$ $17.343)$, respectively. A receiver operating characteristic (ROC) curve analysis was performed to determine the predictability of skip metastasis according to the primary tumor location in the upper portion, primary tumor size $\leq 10 \mathrm{~mm}$, and capsular invasion and ascertain whether the cases fulfilled all three variables. Skip metastases were best predicted according to a primary tumor diameter no larger than $10 \mathrm{~mm}$ (AUC: 0.777) and then according to an upper portion location (AUC:0.731) and capsular invasion (AUC: 0.659). When the cases fulfilled all three risk factors, the specificity was 0.98 , and the AUC was 0.700, as shown in Figure 1.

In the 39 patients with skip metastasis, one patient suffered postoperative hypoparathyroidism and recovered 8 months later and one patient suffered from wound infection. In addition, we compared the tumor- free survival of the two patient groups. As shown in Figure 2, significant differences were not observed $(\mathrm{P}=0.432)$; therefore, skip metastasis should not lead to tumor recurrence or affect the patient's long term survival.

\section{Clinical model of skip metastasis}

Ten PTCs were injected with $0.1 \mathrm{ml}$ carbon nanoparticles into the upper portion of the lobe, and the black-stained lymph nodes were counted and are shown in Table 5. Overall, 7 (70\%) patients did not show black staining of the central lymph node. However, for the lateral lymph nodes (skip black staining), all 10 patients $(100 \%)$ presented black staining in the Level II metastases, 9 patients $(90 \%)$ presented staining in the Level III and IV metastases, and 7 patients $(70 \%)$ presented staining in the Level V metastases. In addition, Level II (61.7\%) had the highest lymph node black staining rate followed by Levels III (55.7\%), V(42.9\%) and IV(33.3\%). 
Table 2: PTC tumor characteristics and lymph node metastasis(n=450)

\begin{tabular}{|c|c|}
\hline Characteristics & Results \\
\hline Multifocality (yes/no) & $74 / 376$ \\
\hline Bilaterality (yes/no/isthmus/isthmus+lobe) & $71 / 359 / 8 / 12$ \\
\hline Capsule invasion (yes/no) & $250 / 200$ \\
\hline Extrathyroid extension (yes/no) & $121 / 329$ \\
\hline Total tumor size $($ mean $\pm \mathrm{SD}, \mathrm{cm})$ & $17.1 \pm 9.7$ \\
\hline Total tumor size $(\leq 10 \mathrm{~mm},>10 \mathrm{~mm})$ & $96 / 244$ \\
\hline Largest tumor size (mean $\pm \mathrm{SD}, \mathrm{mm})$ & $16.2 \pm 10.4$ \\
\hline \multicolumn{2}{|l|}{ Primary tumor location } \\
\hline Upper & 178 \\
\hline Middle & 133 \\
\hline Lower & 121 \\
\hline Isthmus & 18 \\
\hline \multicolumn{2}{|l|}{ Tumor extension } \\
\hline $\mathrm{T} 1$ & 58 \\
\hline $\mathrm{T} 2$ & 18 \\
\hline $\mathrm{T} 3$ & 282 \\
\hline $\mathrm{T} 4$ & 92 \\
\hline Preoperative distant metastasis (no/lung/bone/both) & $438 / 9 / 1 / 2$ \\
\hline \multicolumn{2}{|l|}{ Central neck node number } \\
\hline Harvested & $11.0 \pm 3.0$ \\
\hline Metastatic & $5.9 \pm 3.2$ \\
\hline \multicolumn{2}{|l|}{ Ipsilateral central neck node number } \\
\hline Harvested & $6.3 \pm 2.1$ \\
\hline Metastatic & $3.5 \pm 2.1$ \\
\hline \multicolumn{2}{|l|}{ Lateral neck node } \\
\hline Harvested & $25.9 \pm 11.2$ \\
\hline Metastatic & $6.4 \pm 2.8$ \\
\hline \multicolumn{2}{|l|}{ Lateral neck node metastasis cases } \\
\hline Level II & $184(40.9 \%)$ \\
\hline Level III & $339(75.3 \%)$ \\
\hline Level IV & $328(72.9 \%)$ \\
\hline Level V & $173(38.4 \%)$ \\
\hline
\end{tabular}

\section{DISCUSSION}

Lymph node metastasis is common for PTCs and accounts for $30 \%-80 \%$ of all PTCs, including PTMC [13]. Surgeons frequently elect to perform radical surgery of the metastasized lymph; however, reoperation for PTC recurrence may significantly increase the surgical complications and medical costs and affect the patient's quality of life $[14,15]$. Therefore, preoperative evaluations of lymph node metastasis must be performed to determine the exact extent of neck dissection. The thyroid gland has been reported to contain its own internal lymphatic system and external lymphatic system. Central lymph nodes are the most frequent nodes involved inmetastasis 
Table 3: Comparison of clinicopathological variables between two groups of patients with PTC

\begin{tabular}{|c|c|c|c|}
\hline \multirow[t]{2}{*}{ Variable } & \multicolumn{2}{|c|}{ Skip Metastasis } & \multirow[t]{2}{*}{ P-value } \\
\hline & Present $(n=39)$ & Absent $(n=411)$ & \\
\hline Age $(\leq 45 />45$ years $)$ & $29 / 10$ & $266 / 145$ & 0.227 \\
\hline Sex (male/female) & $12 / 27$ & $108 / 303$ & 0.545 \\
\hline Race (Han/Other) & $38 / 1$ & $404 / 7$ & 0.698 \\
\hline $\operatorname{BMI}\left(<24 / \geq 24 \mathrm{~kg} / \mathrm{m}^{2}\right)$ & $29 / 10$ & $272 / 139$ & 0.300 \\
\hline Chronic disease(yes/no) & $10 / 29$ & $65 / 346$ & 0.116 \\
\hline Autoimmune thyroid disease (yes/no) & $10 / 29$ & $106 / 305$ & 0.984 \\
\hline Graves' disease (yes/no) & $3 / 36$ & $5 / 406$ & 0.055 \\
\hline Nodular goiters (yes/no) & $24 / 15$ & $257 / 154$ & 0.903 \\
\hline $\operatorname{NLR}(\leq 2 />2)$ & $29 / 10$ & $263 / 148$ & 0.195 \\
\hline $\operatorname{PLR}(\leq 200 />200)$ & $39 / 0$ & $391 / 20$ & 0.159 \\
\hline TSH level $(\leq 4.2 />4.2 \mathrm{mU} / \mathrm{L})$ & $31 / 8$ & $332 / 79$ & 0.845 \\
\hline Multifocality (yes/no) & $38 / 1$ & $338 / 73$ & 0.015 \\
\hline Bilaterality (yes/no) & $36 / 3$ & $383 / 28$ & 0.596 \\
\hline Capsule invasion (yes/no) & $33 / 6$ & $217 / 194$ & $<0.001 *$ \\
\hline Extrathyroid extension (yes/no) & $12 / 27$ & $109 / 302$ & 0.615 \\
\hline Total tumor size $(\leq 10 \mathrm{~mm},>10 \mathrm{~mm})$ & $28 / 11$ & $67 / 344$ & $<0.001^{*}$ \\
\hline Primary tumor size $(\leq 10 \mathrm{~mm},>10 \mathrm{~mm})$ & $28 / 11$ & $92 / 319$ & $<0.001 *$ \\
\hline Tumor extension (T1-T2/T3-T4) & $6 / 33$ & $76 / 335$ & 0.631 \\
\hline Primary Tumor & $37 / 2 / 0 / 0$ & $141 / 131 / 121 / 18$ & $<0.001^{*}$ \\
\hline \multicolumn{4}{|l|}{ location(Upper/Middle/Lower/Isthmus) } \\
\hline Preoperative distant metastasis (yes/no) & $0 / 39$ & $12 / 399$ & 0.280 \\
\hline \multicolumn{4}{|l|}{ Central neck node number } \\
\hline Harvested & $10.8 \pm 2.9$ & $11.0 \pm 3.0$ & 0.693 \\
\hline Metastatic & $0.3 \pm 0.6$ & $6.4 \pm 2.8$ & $<0.001$ \\
\hline \multicolumn{4}{|l|}{ Ipsilateral central neck node number } \\
\hline Harvested & $6.8 \pm 1.9$ & $6.3 \pm 1.7$ & 0.095 \\
\hline Metastatic & - & $3.8 \pm 1.9$ & $<0.001$ \\
\hline Lateral neck node metastasis LN number & $5.4 \pm 2.2$ & $6.5 \pm 2.9$ & 0.015 \\
\hline \multicolumn{4}{|l|}{ Lateral neck node metastasis LN cases } \\
\hline Level II & $26(66.7 \%)$ & $158(38.4 \%)$ & $<0.001$ \\
\hline Level III & $23(59.0 \%)$ & $316(87.6 \%)$ & 0.041 \\
\hline Level IV & $2(5.1 \%)$ & $326(79.3 \%)$ & $<0.001$ \\
\hline Level V & $1(2.6 \%)$ & $177(43.1 \%)$ & $<0.001$ \\
\hline Lateral compartment single level metastasis & $27(69.2 \%)$ & $68(16.5 \%)$ & $<0.001$ \\
\hline Lateral compartment double levels metastasis & $11(28.2 \%)$ & $170(41.4 \%)$ & 0.110 \\
\hline Lateral compartment triple levels metastasis & $1(2.6 \%)$ & $128(31.1 \%)$ & $<0.001$ \\
\hline Lateral compartment four levels metastasis & 0 & $45(10.9 \%)$ & 0.030 \\
\hline
\end{tabular}

Abbreviations: BMI: body mass index; NLR: neutrophil-to-lymphocyte ratio; PLR: platelet-to-lymphocyte ratio; TSH: thyroid stimulating hormone; 
Table 4: Multivariate analyses of factors contributing to skip metastasis of PTC

\begin{tabular}{lccc}
\hline Variables & Odds ratio & 95\% CI & P-value \\
\hline Capsule invasion $($ yes/no) & 5.822 & $1.954-17.343$ & $0.002 *$ \\
Primary tumor size $(\leq 10 \mathrm{~mm} />10 \mathrm{~mm})$ & 32.492 & $11.973-88.174$ & $0.006^{*}$ \\
Total tumor size $(\leq 10 \mathrm{~mm} />10 \mathrm{~mm})$ & 4.686 & $0.143-153.101$ & 0.385 \\
Primary tumor location(upper/other sites) & 18.495 & $6.612-51.731$ & $<0.001 *$ \\
\hline
\end{tabular}

followed by the lateral lymph nodes, which indicates that cervical lymph node metastasis occurs in a stepwise fashion. Lymphatic drainage of the thyroid occurs first in the central compartment (Level VI) and then in the lateral neck compartment.

Compared with the general patterns of thyroid lymphatic drainage, skip metastasis, which is defined as negative ipsilateral central and positive ipsilateral lateral compartment lymph nodes, is a specific but not uncommon type of metastasis in patients with PTC [9-11, 16-21] and MTC $[20,22]$. The significance of skip metastasis in PTC patients is still unknown. Compared with the results of previous studies [9-11, 16-21], the present study first evaluated and compared the impact of skip metastases on tumor recurrence and survival and obtained negative results that were inconsistent with the results of previous

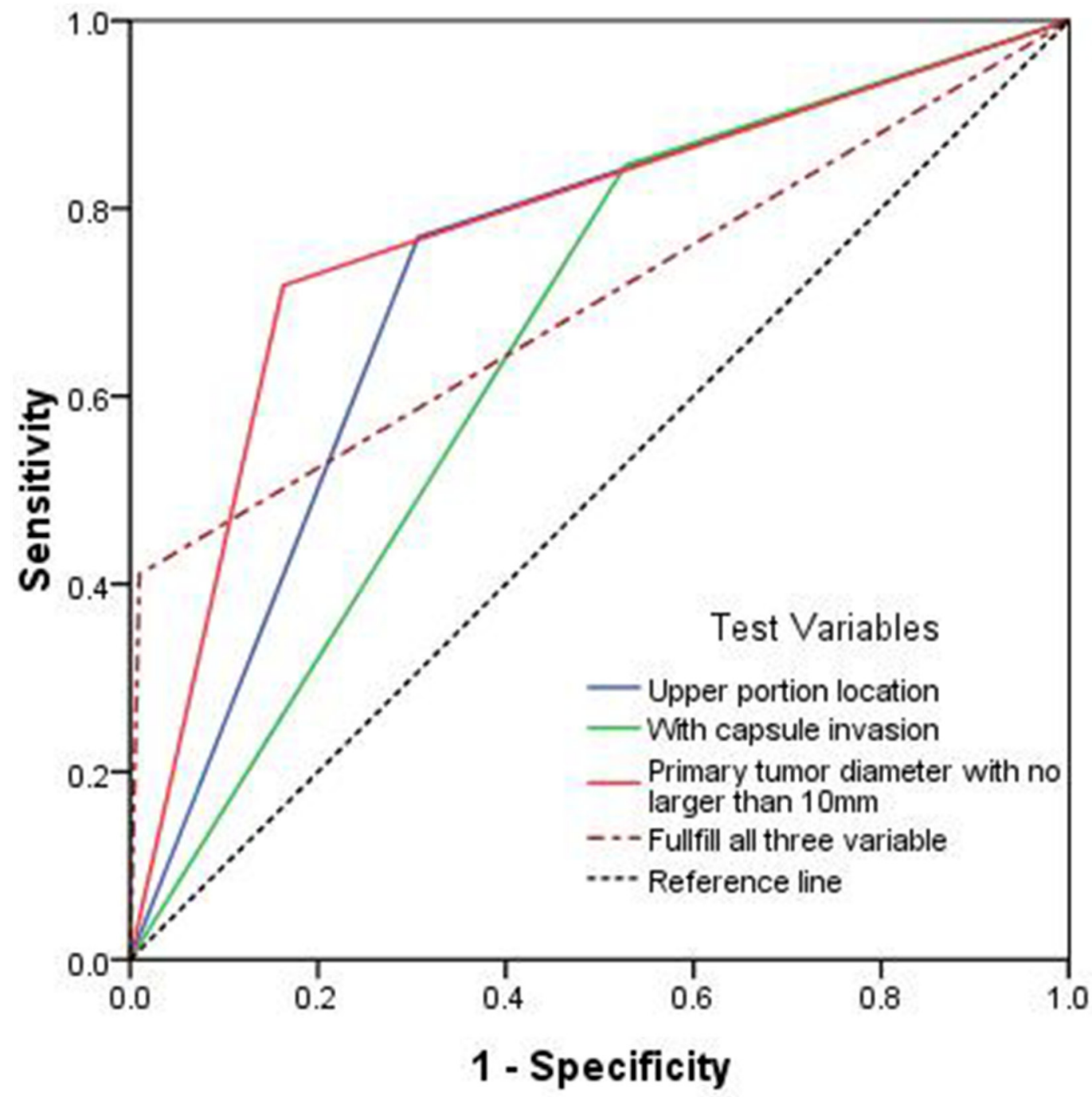

Figure 1: Predictability of skip metastasis shown by a receiver operating characteristic (ROC) curve for primary tumors with a diameter no larger than $10 \mathrm{~mm}$ (AUC: $\mathbf{0 . 7 7 7 )}$ ), tumors located in the upper portion location (AUC: 0.731 ) and tumors presenting capsular invasion (AUC: 0.659). 
studies on non-small-cell lung cancer and colorectal cancer, which indicated that skip metastasis may have a positive impact on prognosis $[23,24]$. The negative impact of skip metastasis on recurrence and survival reported here was likely related to the limited incidence of lymph node metastases as shown in Table 3 .

The incidence of skip metastasis in PTC patients ranges from $3.0 \%$ to $19.7 \%$ [9-11, 16-21]. However, these results were limited by the small sample size of the studies, which had a maximal patients number of 147 . This number is only one third the size of our sample (Table 6). In addition, almost all of the studies were performed in Korea except for two studies. This study is the first report from the Chinese mainland, which accounts for almost $20 \%$ of PTC cases worldwide [1]. The rate of skip metastasis in our present study was 8.6\% (39/450), which is comparable to that of certain studies $[11,18$,
$19,21]]$ but much lower than other reports $[9,10,16$, 17, 20]. The possible reason for this difference could be heterogeneous patient populations in the samples [9]. In addition, our study first reported 7 cases with contralateral central lymph node metastasis (10 lymph nodes metastases overall) and ipsilateral lateral neck lymph node metastasis but without ipsilateral central neck lymph node metastasis, which may indicate migration via the lymphatic drainage across the center median to the contralateral central part (VI region).

The risk factors associated with skip metastasis have been discussed in previous studies (Table 6). However, these factors were not observed in two studies [20, 21]; therefore, these studies did not include risk factors related to skip metastasis. Similar to previous studies $[10,11]$, we found that a primary tumor located in the upper portion was a predictive factor. This predictive factor could be

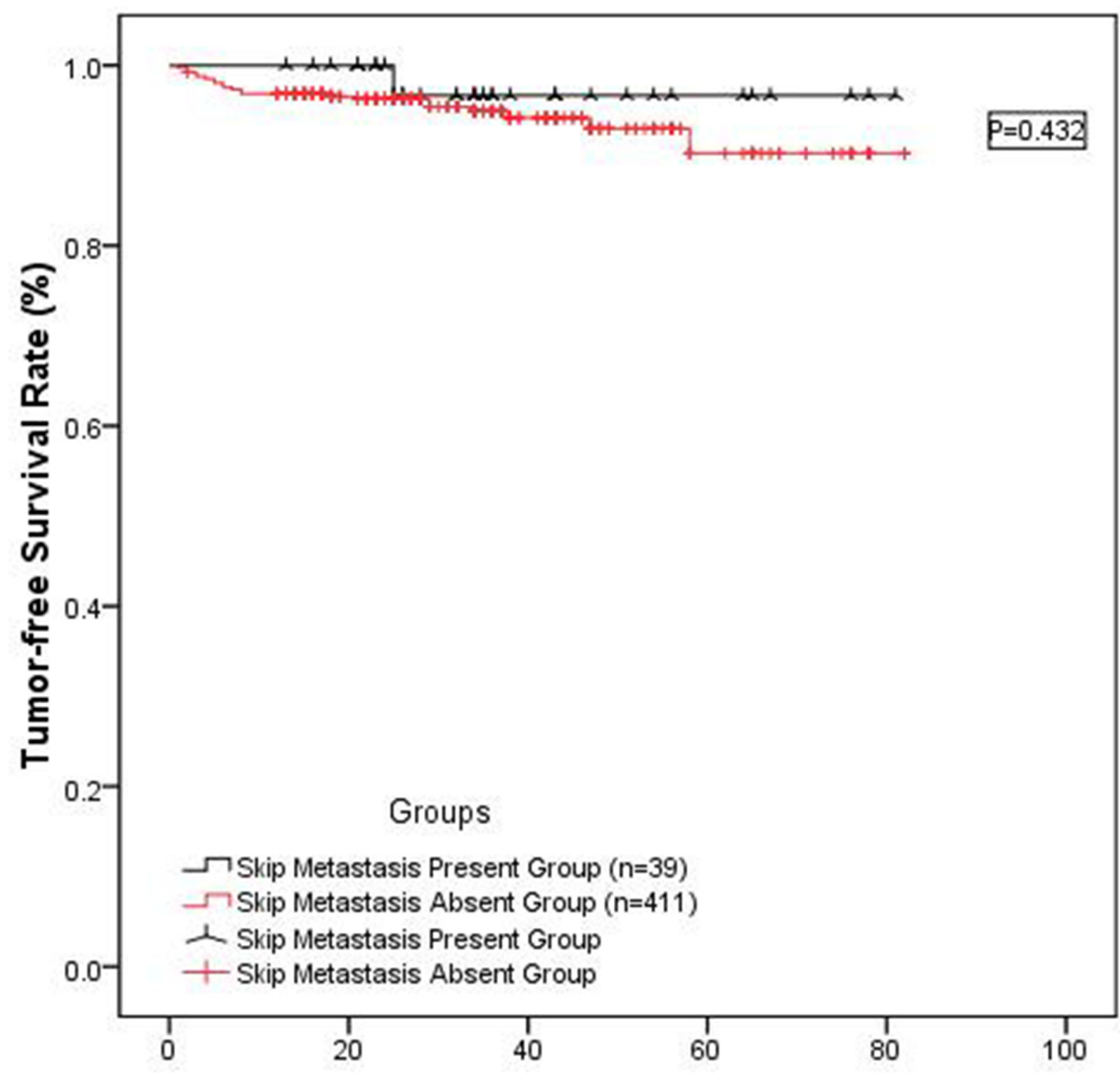

Follow-up Months After Operation

Figure 2: Long-term tumor-free survival rate between 39 patients presenting skip metastasis and the 411 patients without skip metastasis. The two groups of patients did not show significant differences $(\mathrm{P}=0.432)$. 
Table 5: Prospective study on skip metastasis using carbon nanoparticles

\begin{tabular}{|c|c|c|c|c|c|c|c|c|c|c|}
\hline patients & $\begin{array}{c}\text { Total } \\
\text { harvest } \\
\text { lymph } \\
\text { node } \\
\text { number }\end{array}$ & $\begin{array}{c}\text { ipsilateral } \\
\text { central } \\
\text { harvest } \\
\text { lymph } \\
\text { node } \\
\text { number }\end{array}$ & $\begin{array}{l}\text { ipsilateral } \\
\text { central } \\
\text { lymph } \\
\text { node black } \\
\text { staining } \\
\text { number(\%) }\end{array}$ & $\begin{array}{c}\text { ipsilateral } \\
\text { lateral } \\
\text { harvest } \\
\text { lymph } \\
\text { node } \\
\text { number }\end{array}$ & $\begin{array}{l}\text { ipsilateral } \\
\text { lateral } \\
\text { lymph } \\
\text { node black } \\
\text { staining } \\
\text { number(\%) }\end{array}$ & $\begin{array}{c}\text { Level II } \\
(\%)\end{array}$ & $\begin{array}{l}\text { Level } \\
\text { III(\%) }\end{array}$ & $\begin{array}{l}\text { Level } \\
\text { IV(\%) }\end{array}$ & $\begin{array}{l}\text { Level } \\
\text { V(\%) }\end{array}$ & $\begin{array}{c}\text { Skip } \\
\text { black } \\
\text { staining } \\
\text { (yes/ } \\
\text { no) }\end{array}$ \\
\hline 1 & 62 & 8 & $1(12.5 \%)$ & 54 & $25(46.3 \%)$ & $5(50 \%)$ & $0(0 \%)$ & $0(0 \%)$ & $20(80 \%)$ & No \\
\hline 2 & 24 & 3 & $0(0 \%)$ & 21 & $10(47.6 \%)$ & $4(57.1 \%)$ & $3(75 \%)$ & $1(14.3 \%)$ & $2(66.7 \%)$ & Yes \\
\hline 3 & 28 & 7 & $0(0 \%)$ & 21 & $8(38.1 \%)$ & $2(66.7 \%)$ & $4(80.0 \%)$ & $1(16.7 \%)$ & $1(14.3 \%)$ & Yes \\
\hline 4 & 21 & 5 & $3(60 \%)$ & 16 & $12(75 \%)$ & $2(100 \%)$ & $3(75 \%)$ & $5(83.3 \%)$ & $2(50 \%)$ & No \\
\hline 5 & 21 & 4 & $1(25 \%)$ & 17 & $7(41.2 \%)$ & $1(33.3 \%)$ & $4(100 \%)$ & $2(40 \%)$ & $0(0 \%)$ & No \\
\hline 6 & 27 & 6 & $0(0 \%)$ & 21 & $11(52.4 \%)$ & $2(66.7 \%)$ & $5(100 \%)$ & $4(50 \%)$ & $0(0 \%)$ & Yes \\
\hline 7 & 29 & 5 & $0(0 \%)$ & 24 & $12(50 \%)$ & $4(100 \%)$ & $5(83.3 \%)$ & $3(37.5 \%)$ & $0(0 \%)$ & Yes \\
\hline 8 & 39 & 8 & $0(0 \%)$ & 31 & $11(35.5 \%)$ & $3(60 \%)$ & $5(55.6 \%)$ & $2(16.7 \%)$ & $1(20 \%)$ & Yes \\
\hline 9 & 29 & 5 & $0(0 \%)$ & 24 & $14(58.3 \%)$ & $4(80 \%)$ & $4(50 \%)$ & $4(66.7 \%)$ & $2(40 \%)$ & Yes \\
\hline 10 & 30 & 3 & $0(0 \%)$ & 27 & $7(25.9 \%)$ & $2(40 \%)$ & $1(16.7 \%)$ & $2(25 \%)$ & $2(25 \%)$ & Yes \\
\hline Average & 31 & 5.4 & $0.5(9.3 \%)$ & 25.6 & $11.7(45.7 \%)$ & $2.9(61.7 \%)$ & $3.4(55.7 \%)$ & $2.4(33.3 \%)$ & $3(42.9 \%)$ & $7(70 \%)$ \\
\hline
\end{tabular}

Table 6: Literature review for skip metastasis in PTCs

\begin{tabular}{|c|c|c|c|c|c|}
\hline Author & Country & $\begin{array}{c}\text { Publication } \\
\text { year }\end{array}$ & Included patients & Skip rate(\%) & Risk factors \\
\hline Machens et al [20] & Germany & 2004 & 66 & $13(19.7 \%)$ & No features \\
\hline Chung et al [21] & Korea & 2009 & 39 & $3(7.7 \%)$ & No features \\
\hline Koo et al [16] & Korea & 2010 & 45 & $12(17.1 \%)$ & $\begin{array}{l}\text { Multifocal primary tumor; } \\
\text { positive LN involvement } \\
\text { in all lateral levels }\end{array}$ \\
\hline Lee et al [19] & Korea & 2007 & 46 & $1(3.0 \%)$ & No description \\
\hline Roh et al [18] & Korea & 2008 & 52 & $5(9.6 \%)$ & No description \\
\hline Lim et al [9] & Korea & 2012 & 90 & $17(19.0 \%)$ & $\begin{array}{l}\text { Fewer lymphovascular } \\
\text { invasion; extracapsular } \\
\text { spread }\end{array}$ \\
\hline Kliseska et al [17] & Croatia & 2012 & 42 & $8(19.5 \%)$ & No description \\
\hline Park et al [10] & Korea & 2012 & 147 & $32(21.8 \%)$ & $\begin{array}{l}\text { Upper pole; tumors } \leq 10 \\
\text { mm;Unifocal }\end{array}$ \\
\hline Lee et al [11] & Korea & 2013 & 131 & $9(6.9 \%)$ & Upper part \\
\hline Present study & China & 2016 & 450 & $39(8.7 \%)$ & $\begin{array}{l}\text { Capsule invasion; Primary } \\
\text { tumor size } \leq 10 \mathrm{~mm} \text {; upper } \\
\text { portion location }\end{array}$ \\
\hline
\end{tabular}

explained by the nature of the lymphatic drainage system of the thyroid gland because tumor cells from PTC located in the upper lobe were more likely to be transported to the lateral lymph nodes along the superior thyroid artery
[25] and tumor cells from the mid-lower region of the gland were more likely to be transported to the CLN. The lymphatic drainage system explains why skip metastasis frequently occurred in the upper lobe PTCs(39 cases) 
except for two cases in which the tumors were located in the middle portion. In addition, lateral node metastasis preferentially occurred along the lymphatic chain as reported by previous studies. Level III nodes were the most frequently involved nodes, followed by Levels IV, II and V [18]. However, the 39 patients with lymph node skip metastasis had a much higher rate of Level II but a lower rate of Level IV and V lymph node involvement, which was mainly because of location of the primary tumors on the upper portion of the gland. In addition, our results indicated that the 39 cases with skip metastasis showed a greater number of single-level metastases and fewer tripleand quadruple-level metastases, which may be related to the smaller tumor size and upper portion tumor location. In addition to the upper portion, a primary tumor size no larger than $10 \mathrm{~mm}$ was another risk factor because skip metastasis is more frequent in less aggressive PTCs, such as PTMC $[9,20]$. In addition, our study showed that skip metastasis was much more common in PTC patients with primary tumor capsular invasion, which was consistent with a previous study [9]. Lymphatic systems that bypass the central lymph node compartment may represent the most likely hypothesis for skip metastasis. However, false negative findings caused by limited lymph node sampling or misdiagnoses during routine histopathology may also contribute to the incidence of skip metastasis $[9,26]$.

All three risk factors related to skip metastasis were observed using our simulation experiments in which $0.1 \mathrm{ml}$ of carbon nanoparticles were injected into the upper portion of the lobe in ten patients. The rate of black staining in the central and lateral lymph nodes was calculated, and the results showed that $70 \%$ of the patients showed skip black staining, all of the patients showed Level II lymph node black staining, and $90 \%$ of patients had Level III and IV, and 70\% of patients had Level V lymph node black staining, respectively. The results of our prospective simulation experiment were consistent with the results of a retrospective study and further supported our conclusions. Carbon nanoparticles have been used to guide central neck dissection [27] or identify and protect the parathyroid [28]. However, this study is the first to use this method to simulate skip metastasis and confirm the risk factors. The diameter of the carbon nanoparticles is $150 \mathrm{~nm}$ [28], which is much smaller than the diameter of a tumor cell. Therefore, lymph node black staining is able to simulate the metastasis of tumor cells to lymph nodes. However, additional investigations are needed to confirm our results.

Our study was limited by its retrospective nature. In addition, our study enrolled only PTC patients who accepted therapeutic lateral compartment dissection (with FNAC-proven metastasis), which is similar to previous reports. FNAC had nearly $10-20 \%$ false negatives, and latent lateral metastases were detected in more than $50 \%$ of the patients who received prophylactic lateral compartment dissection [29]. Additional factors and more accurate detection are required to predict skip metastasis after prophylactic lateral compartment dissection, which is not recommended by ATA, ETA or CTA guidelines.

In conclusion, the rate of skip metastasis in the patients presenting PTC was $8.7 \%$. Therefore, the lateral compartment should be carefully examined for skip metastases, especially for PTC patients who present primary tumors in the upper portion, have a primary tumor size $\leq 10 \mathrm{~mm}$ or show invasion of the tumor capsule.

\section{MATERIALS AND METHODS}

This study was approved by the local institutional review boards, and approval and informed consent were obtained from all patients before the study began. The postoperative histology medical records of all of the PTC patients who underwent simultaneous total thyroidectomy with the central compartment LND and ipsilateral therapeutic lateral compartment LND were reviewed and analyzed. Cases with one of the following items were excluded from our study: revision surgery, history or presence of other head and neck carcinomas, other types of thyroid carcinoma, negative lateral lymph node metastases in postoperative histopathologic examination, focal "berry-picking" for CLN or LLN compartments, or less than total thyroidectomy combined with bi-CLN and ipsilateral LLN dissection.

Preoperative ultrasonography and neck enhanced CT and/or MRI were performed by experienced technicians and used to evaluate the tumor size, location, presence of nodal metastases and other tumor characteristics. The imaging results were co-evaluated by two readers: a radiologist with at least 15 years of experience and a surgeon with at least 20 years of experience. For the suspicious PTCs (i.e., central necrosis or cystic change, dense cortical enhancement, or calcification), fine-needle aspiration biopsy (FNAB) and cytological BRAF ${ }^{\mathrm{V} 600 \mathrm{E}}$ mutation were performed to confirm the diagnosis. All lateral neck lymph node compartment dissections were performed for PTC patients who were confirmed to have clinical evidence of positive lateral neck nodes (no prophylactic lateral lymph node dissection) via FNAB or thyroglobulin assessment. The histopathological evaluation of the thyroid specimens was performed by experienced pathologists who had at least 10 years of experience and had diagnosed over 500 PTC cases.

The number of LNMs was calculated and analyzed with respect to neck level. The lateral compartment and central compartment were divided into four sub-parts: ipsilateral and contralateral central compartments as well as prelaryngeal (Delphian) and pretracheal compartments. Superior central lymph node compartment dissection was performed laterally on the thyroid cartilage notch to the carotid sheaths, posteriorly to the prevertebral fascia, including VI A (superficial right recurrent laryngeal nerve) and VI B (posterior of right recurrent laryngeal nerve) 
and inferiorly to the innominate vein. The lateral cervical lymph nodes were classified into four neck levels (II-V) based on the criteria from the American Head and Neck Society [30] and American Thyroid Association (ATA) [31]. In every case, the lateral compartment was radically modified superiorly to the posterior belly of the digastric muscle, inferiorly to the subclavian vein, and laterally to the anterior border of the trapezius muscle. The central and lateral compartments were removed in whole pieces and then divided into sublevels according to the intraoperative mark.

CLN dissection was performed after the total thyroid was removed, bilateral CLN dissection was performed routinely, and radical lymph node dissection, including the lateral lymph node compartment, was performed for radical therapeutic purposes [32]. Tumor locations were categorized as the isthmus and theupper, middle, and lower portion based on the results of the preoperative ultrasonography with a longitudinal view. In multifocal cases, the analysis was based on the largest tumor diameter. In our study, skip metastasis was defined according to previous reports [9-11] as an ipsilateral lateral lymph node metastasis with no positive nodes in the central compartment.

Clinical and pathological variables that may be related to skip metastasis were compared between the skip metastasis group and the control group. All variables with a value of $\mathrm{P}<0.05$ were included in the multivariate analysis, and comparisons were performed among the predictive factors using the ROC Curve. To verify our predictive factors, we performed prospective research on 10 PTC patients who presented with preoperative FNAC-supported lateral metastasis and PTCs located in middle or lower portion of the lobe. When freeing flaps is ready, ultrasonography was used to guide an injection of $0.1 \mathrm{ml}$ carbon nanoparticles into the upper portion of the lobe, with nearly $0.5 \mathrm{~cm}$ maintained between the injection site and the thyroid capsule (anterior, lateral and posterior)[28]. The diffusion diameter of the $0.1 \mathrm{ml}$ carbon nanoparticles in the thyroid gland under ultrasonography was approximately $10 \mathrm{~mm}$. The surgical procedure was performed routinely 10 minutes after the injection, and the total number of harvested and black-stained lymph nodes of the ipsilateral center compartment and sub-levels of the lateral compartment were separately counted by two surgeons and then by one experienced pathologist. If one lymph node was not stained completely, it was counted as a stained lymph node. When the number of lymph nodes was inconsistent, the investigators were either consulted or the average value of all evaluations was used.

Continuous and categorical data were expressed as the mean $\pm \mathrm{SD}$ and the rates, respectively. The differences between continuous data and categorical data were compared and analyzed using the MannWhitney U test and the chi-square or Fisher's exact test (2-tailed) if necessary. Univariate analyses were performed for the association between skip metastases and clinicopathological factors using the Pearson chisquare test or Fisher's exact test. All of the variables with values of $\mathrm{P}<0.05$ were included in the multivariate analysis to assess the independent predictive factors using a Cox regression analysis. The odds ratios (ORs) and 95\% relative confidence intervals (CIs) were calculated to determine the relevance of all potential predictors. The predictability of skip metastasis according to the multivariate analysis was assessed using the ROC curve. A 2-tailed P-value of $<0.05$ was considered significant. SPSS software (SPSS 17, Inc., Chicago, IL, USA) was used to manage the data and for the statistical analyses.

\section{Abbreviations}

PTC: papillary thyroid carcinoma; CND: central neck dissection; LND: lateral neck dissection; CT: computed tomography; MRI: magnetic resonance imaging; ATA: American Thyroid Association; FNAB: fine-needle aspiration biopsy; PTMC: Papillary thyroid microcarcinoma

\section{Author contributions}

The first authors of this manuscript are Lei Jianyong, Zhong Jinjing and Jiang Ke. These three contributed equally to this study and should be co-first authors. Lei JY and Zhu JQ performed research and wrote the first draft. All authors contributed to the design and interpretation of the study and to further drafts. Zhu JQ is the guarantor.

\section{CONFLICTS OF INTEREST}

No benefits in any form have been received or will be received from a commercial party related directly or indirectly to the subject of this article.

\section{GRANT SUPPORT}

This study was supported by grants from Sichuan Provience Science and Technology Project of China (No.2017SZ0139)

\section{REFERENCES}

1. Chen W, Zheng R, Baade PD, Zhang S, Zeng H, Bray F, Jemal A, Yu XQ, He J. Cancer statistics in China, 2015. CA Cancer J Clin. 2016; 66:115-132.

2. Siegel RL, Miller KD, Jemal A. Cancer statistics, 2016. CA Cancer J Clin. 2016; 66:7-30.

3. Liu X, Zhu L, Wang Z, Cui D, Chen H, Duan Y, Shen M, Lu H, Zhang Z, Chen J, Alexander EK, Yang T, Wang X. Evolutionary features of thyroid cancer in patients with thyroidectomies from 2008 to 2013 in China. Sci Rep. 2016;6:28414. 
4. Jeon MJ, Kim WG, Choi YM, Kwon H, Song DE, Lee YM, Sung TY, Yoon JH, Hong SJ, Baek JH, Lee JH, Ryu JS, Kim TY, et al. Recent Changes in the Clinical Outcome of Papillary Thyroid Carcinoma With Cervical Lymph Node Metastasis. J Clin Endocrinol Metab. 2015; 100:3470-3477.

5. Ieni A, Barresi V, Cardia R, Licata L, Di Bari F, Benvenga $\mathrm{S}$, Tuccari G. The micropapillary/hobnail variant of papillary thyroid carcinoma: A review of series described in the literature compared to a series from one southern Italy pathology institution. Rev Endocr Metab Disord. 2016; 17:521-527.

6. Shi C, Guo Y, Lv Y, Nanding A, Shi T, Qin H, He J. Clinicopathological Features and Prognosis of Papillary Thyroid Microcarcinoma for Surgery and Relationships with the BRAFV600E Mutational Status and Expression of Angiogenic Factors. PLoS One. 2016; 11:e0167414.

7. Cushing SL, Palme CE, Audet N, Eski S, Walfish PG, Freeman JL. Prognostic factors in well-differentiated thyroid carcinoma. Laryngoscope. 2004; 114:2110-2115.

8. Machens A, Hinze R, Thomusch O, Dralle H. Pattern of nodal metastasis for primary and reoperative thyroid cancer. World J Surg. 2002; 26:22-28.

9. Lim YC, Koo BS. Predictive factors of skip metastases to lateral neck compartment leaping central neck compartment in papillary thyroid carcinoma. Oral Oncol. 2012; 48:262-265.

10. Park JH, Lee YS, Kim BW, Chang HS, Park CS. Skip lateral neck node metastases in papillary thyroid carcinoma. World J Surg. 2012; 36:743-747.

11. Lee YS, Shin SC, Lim YS, Lee JC, Wang SG, Son SM, Kim IJ, Lee BJ. Tumor location-dependent skip lateral cervical lymph node metastasis in papillary thyroid cancer. Head Neck. 2014; 36:887-891.

12. Uruno T, Miyauchi A, Shimizu K, Tomoda C, Takamura Y, Ito Y, Miya A, Kobayashi K, Matsuzuka F, Amino N, Kuma $\mathrm{K}$. Usefulness of thyroglobulin measurement in fine-needle aspiration biopsy specimens for diagnosing cervical lymph node metastasis in patients with papillary thyroid cancer. World J Surg. 2005; 29:483-485.

13. Lee YM, Sung TY, Kim WB, Chung KW, Yoon JH, Hong SJ. Risk factors for recurrence in patients with papillary thyroid carcinoma undergoing modified radical neck dissection. Br J Surg. 2016; 103:1020-1025.

14. Wada N, Duh QY, Sugino K, Iwasaki H, Kameyama K, Mimura T, Ito K, Takami H, Takanashi Y. Lymph node metastasis from 259 papillary thyroid microcarcinomas: frequency, pattern of occurrence and recurrence, and optimal strategy for neck dissection. Ann Surg. 2003; 237:399-407.

15. Nixon IJ, Wang LY, Ganly I, Patel SG, Morris LG, Migliacci JC, Tuttle RM, Shah JP, Shaha AR. Outcomes for patients with papillary thyroid cancer who do not undergo prophylactic central neck dissection. Br J Surg. 2016; 103:218-225.

16. Koo BS, Choi EC, Park YH, Kim EH, Lim YC. Occult contralateral central lymph node metastases in papillary thyroid carcinoma with unilateral lymph node metastasis in the lateral neck. J Am Coll Surg. 2010; 210:895-900.

17. Kliseska E, Makovac I. Skip metastases in papillary thyroid cancer. Coll Antropol. 2012; 36:59-62.

18. Roh JL, Kim JM, Park CI. Lateral cervical lymph node metastases from papillary thyroid carcinoma: pattern of nodal metastases and optimal strategy for neck dissection. Ann Surg Oncol. 2008; 15:1177-1182.

19. Lee BJ, Wang SG, Lee JC, Son SM, Kim IJ, Kim YK. Level IIb lymph node metastasis in neck dissection for papillary thyroid carcinoma. Arch Otolaryngol Head Neck Surg. 2007; 133:1028-1030.

20. Machens A, Holzhausen HJ, Dralle H. Skip metastases in thyroid cancer leaping the central lymph node compartment. Arch Surg. 2004; 139:43-45.

21. Chung YS, Kim JY, Bae JS, Song BJ, Kim JS, Jeon HM, Jeong SS, Kim EK, Park WC. Lateral lymph node metastasis in papillary thyroid carcinoma: results of therapeutic lymph node dissection. Thyroid. 2009; 19:241-246.

22. Tavares MR, Michaluart P, Jr., Montenegro F, Arap S, Sodre M, Takeda F, Brandao L, Toledo S, Ferraz A. Skip metastases in medullary thyroid carcinoma: a single-center experience. Surg Today. 2008; 38:499-504.

23. Prenzel KL, Monig SP, Sinning JM, Baldus SE, Gutschow CA, Grass G, Schneider PM, Holscher AH. Role of skip metastasis to mediastinal lymph nodes in non-small cell lung cancer. J Surg Oncol. 2003; 82:256-260.

24. Shiozawa M, Akaike M, Yamada R, Godai T, Yamamoto N, Saito H, Sugimasa Y, Takemiya S, Rino Y, Imada T. Clinicopathological features of skip metastasis in colorectal cancer. Hepatogastroenterology. 2007; 54:81-84.

25. Ito Y, Tomoda C, Uruno T, Takamura Y, Miya A, Kobayashi K, Matsuzuka F, Kuma K, Miyauchi A. Papillary microcarcinoma of the thyroid: how should it be treated? World J Surg. 2004; 28:1115-1121.

26. Hosch SB, Stoecklein NH, Pichlmeier U, Rehders A, Scheunemann P, Niendorf A, Knoefel WT, Izbicki JR. Esophageal cancer: the mode of lymphatic tumor cell spread and its prognostic significance. J Clin Oncol. 2001; 19:1970-1975.

27. Yu W, Cao X, Xu G, Song Y, Li G, Zheng H, Zhang N. Potential role for carbon nanoparticles to guide central neck dissection in patients with papillary thyroid cancer. Surgery. 2016;160:755-61.

28. Zhu J, Tian $\mathrm{W}, \mathrm{Xu} Z$, Jiang K, Sun H, Wang P, Huang T, Guo Z, Zhang H, Liu S, Zhang Y, Cheng R, Zhao D, et al. Expert consensus statement on parathyroid protection in thyroidectomy. Ann Transl Med. 2015; 3:230.

29. Ito Y, Jikuzono T, Higashiyama T, Asahi S, Tomoda C, Takamura Y, Miya A, Kobayashi K, Matsuzuka F, Kuma K, Miyauchi A. Clinical significance of lymph node metastasis of thyroid papillary carcinoma located in one lobe. World J Surg. 2006; 30:1821-1828. 
30. Carty SE, Cooper DS, Doherty GM, Duh QY, Kloos RT, Mandel SJ, Randolph GW, Stack BC Jr, Steward DL, Terris DJ, Thompson GB, Tufano RP, Tuttle RM, et al. Consensus statement on the terminology and classification of central neck dissection for thyroid cancer. Thyroid. 2009; 19:1153-1158.

31. Haugen BR, Alexander EK, Bible KC, Doherty GM, Mandel SJ, Nikiforov YE, Pacini F, Randolph GW, Sawka AM, Schlumberger M, Schuff KG, Sherman SI, Sosa JA, et al. 2015 American Thyroid Association Management
Guidelines for Adult Patients with Thyroid Nodules and Differentiated Thyroid Cancer: The American Thyroid Association Guidelines Task Force on Thyroid Nodules and Differentiated Thyroid Cancer. Thyroid. 2016; 26:1-133.

32. Javid M, Graham E, Malinowski J, Quinn CE, Carling T, Udelsman R, Callender GG. Dissection of Levels II Through V Is Required for Optimal Outcomes in Patients with Lateral Neck Lymph Node Metastasis from Papillary Thyroid Carcinoma. J Am Coll Surg. 2016; 222:1066-1073. 